\title{
THE
}

\section{Fishing Effort Coordination and Revenue Pooling Arrangement in Fishery Comanagement : Evidence from Japan}

Hirotsugu Uchida

University of Rhode Island

Follow this and additional works at: https://digitalcommons.uri.edu/enre_facpubs

Terms of Use

All rights reserved under copyright.

\section{Citation/Publisher Attribution}

Uchida, H. (2010). "Fishing Effort Coordination and Revenue Pooling Arrangement in Fishery Comanagement: Evidence from Japan." KMI International Journal of Maritime Affairs and Fisheries. 1(2), 1-26.

Available at: https://www.dbpia.co.kr/Journal/ArticleDetail/NODE01782859

This Article is brought to you for free and open access by the Environmental and Natural Resource Economics at DigitalCommons@URI. It has been accepted for inclusion in Environmental and Natural Resource Economics Faculty Publications by an authorized administrator of DigitalCommons@URI. For more information, please contact digitalcommons-group@uri.edu. 


\title{
Fishing effort coordination and revenue pooling arrangement in fishery comanagement: Evidence from Japan
}

\author{
Hirotsugu Uchida ${ }^{*}$
}

\begin{abstract}
This paper analyzes the impact of fishing effort coordination and revenue pooling arrangement on overall returns from fishery comanagement. Using the survey data collected from the Japanese fishery management organizations (FMOs) in 2005, we focused on two management measures employed by FMOs: fishing effort coordination and revenue pooling arrangement. We found that FMOs with both effort coordination and pooling arrangement outperformed those with neither or only with either one. The specific activities that these FMOs are engaged in that had positive impacts on their economic performance include marketing and harvest control. Marketing in general had a significant positive effect for FMOs with both measures, but we also found that no single specific marketing activity is a silver bullet, suggesting that the specifics vary from case to case. Our analysis provides a hint of what a fishery comanagement group can do in order to be successful in their management effort.
\end{abstract}

Key words: fishery comanagement, effort coordination, pooling arrangement, Japan

\footnotetext{
* Assistant Professor, Department of Environmental and Natural Resource Economics, University of Rhode Island, Rhode Island, USA. E-mail : uchida@uri.edu, Tel. : 1-401-874-2238

This research received support from the University of California Pacific Rim Research Program Research Grant and the Rhode Island Agricultural Experiment Station (Contribution number 5224).
} 


\section{Introduction}

Collective management in fisheries has garnered much attention in recent years as an alternative to conventional top-down regulations and completely decentralized scheme such as individual transferable quotas. While the definition of collective management?or comanagement-differs across the literature (Jentoft, 2003), the key feature here is that local fishermen form a group to jointly manage the common pool resource they exploit. It can take various forms, including harvester cooperatives in Alaska, sector allocations in New England (Johnston and Sutinen, 2009) and fishery cooperative communities in South Korea (MOMAF, 2007).

Collective fishery management as a scheme is anything but new. It is rather the norm in artisanal fisheries (Jentoft, 2003) and there are many examples of fishery comanagement around the world (Wilson, Nielsen and Dengbol, 2003; Cunningham and Bostock, 2005; Townsend, Shotton and Uchida, 2008). There is an abundance of literature attempting to synthesize the lessons learned from these case studies, not just in fisheries but in the context of common pool resources in general (e.g., Ostrom, 1990; Baland and Platteau, 1996; Ostrom et al., 2002). Some of the key lessons listed in these literatures include the importance of well defined boundaries, homogeneous member characteristics, immobile resource, conflict resolution mechanisms and so on. What seems to be lacking in these lists, however, is what these comanagement groups can do as part of their daily fishing operations and institutional arrangements that may lead to the success of the comanagement.

Examining fishery comanagement in the coastal fisheries of Japan provides some valuable lessons. The advantage of studying Japanese fishery comanagement is their abundance and variety of cooperatives. These cooperatives function under the same national fishery rules and laws and, to certain extent, their cultural and social characteristics are identical. This enables us to utilize wide variations in key fishery-related variables while controlling for other influential and difficult-to-observe disturbances. There are several studies examining the framework, both institutional and legal, of Japanese fishery comanagement (e.g., Cancino, Uchida and Wilen, 2007). However, our focus is on the "software" of comanagement and there are two basic and important components of fishery comanagement for its success: effort coordination and pooling arrangement (Uchida, 2009).

There are several important questions about the actual relationships and interactions between effort coordination and pooling arrangements employed by the FMOs. In the literature, pooling arrangements are thought of as supporting systems that help effort coordination operations function effectively (Gaspart and Seki, 2003; Hasegawa, 1985; Baba, 1991). However, the literature on this topic is drawn from a few select cases and does not provide cross-sectional overview of how these schemes are actually employed and how they perform. Whether effort coordination and pooling arrangements bring higher economic returns in 
the first place is an empirical question that may be important to sustainable fishery comanagement. Effort coordination and pooling arrangements can potentially change the way fishermen do fishing by replacing individualistic competition (race to fish) with behavior more similar to a corporate or sole owner style of operation. But making such operational and institutional changes involves long negotiations and, once implemented, a level of monitoring and enforcement effort, which all mount to significant total costs. Since fisheries are no different than any other economic activities, it is vital that implementation of these arrangements bring higher economic return for successful fishery comanagement. Some of the key questions are: Are effort coordination and pooling arrangement generally employed as a pair? Is the performance better when effort coordination and pooling arrangements perform better if they are implemented together rather than individually? If so, in what ways are such outcome achieved? The main contribution of this paper is to provide answers to these questions.

Our results show that members of FMOs with both effort coordination and pooling arrangements had higher economic performance, defined as the revenue per fishing hour, than FMOs with either one or neither of these arrangements. FMOs with only effort coordination or pooling arrangements had positive estimated impact on the economic performance but statistically insignificant compared to FMOs with neither feature, which highlights the importance of having both implemented. We also found that among various management activities that FMOs are engaged in, marketing and harvesting control had the most impact on economic performance.

This paper is organized as follows. In the next section we will briefly explain what are effort coordination and pooling arrangement and why and how they are important in fishery comanagement. The following section describes the data used for our analysis, followed by the section on empirical strategies employed. Section on estimation results will follow and the last section concludes.

\section{Effort coordination and pooling arrangement}

Coastal fishery management in Japan is, for the most part, carried out by the local fishermen's group known as Fishery Cooperative Association (FCA). Members of FCAs are mostly fishing households and "small" companies, as defined by the number of employees and gross tonnage of the vessels owned. The functions of FCAs are similar to other harvester cooperatives and include joint purchases of inputs (e.g., fuel, ice and boxes), administration of ex-vessel markets and provision of insurance and credit to members. FCAs are usually associated with specific coastal communities that historically have depended on fisheries resources. Each FCA typically encompasses all the fisheries within that community or communities' jurisdiction. A number of diverse fisheries?both 
in terms of targeted species and gear used?may be under the auspices of any FCA.

In addition to conventional functions, FCAs play the unique role of managing fishing rights. Fishing rights are defined over a parcel of coastal water, typically in front of the community which an FCA belongs. The borders are defined often by the municipal boundaries then extending certain distance from the shore. The extent of the boundaries from the coast depends partly on the topology of ocean floor and neighboring communities. Fishing rights are granted and protected by law and restricts commercial fishing to only the permitted members of an FCA. In this sense, fishing rights is analogous to territorial use rights for fishing (TURFs) (Christy, 1982). ${ }^{2}$

Comanagement of coastal fisheries is carried out by fishery management organizations (FMOs). An FMO is defined by the Ministry of Agriculture, Forestry and Fisheries as a group of fishers who share the same fishing ground and/or operate in the same fishery and are collectively engaged in resource and/or harvest management according to mutually agreed rules. FMOs are autonomous organizations and some of Japan's FMOs have been in operation for decades. Since it was placed at the center of national fishery management policy in the early 1980s, the number of FMOs continues to rise, with 1,608 FMOs nationwide by, 2003 (MAFF, 2006). FMOs and FCAs are interrelated in number of ways: nearly $95 \%$ of FMOs are operated by a parent FCA or its affiliate organization. As such, the operation of FMOs are supported and utilizing the institutional infrastructures of FCAs and fishing rights.

FMOs and their associated FCAs and fishing rights are all institutional framework under which fishery comanagement groups operate. For FMOs to be successful, they must at minimum generate tangible benefits to the participating members that surpass not only the status quo but those of non-participants. ${ }^{3}$ The question is how to achieve such an outcome in the context of fishery comanagement. While there could be numerous activities and ways of doing business that would achieve this goal, we claim that they can be put into two very broad components: effort coordination and pooling arrangement.

Effort coordination involves individual fishing operations that are coordinated with the goal of increasing the efficiency of the overall fishing effort. This includes, but is not limited to, eliminating the race-to-fish incentive and avoiding congestion at fishing grounds, which also reduces potential damage and loss of fishing gear. Typical methods employed to achieve these objectives are fishing-ground rotations and/or assignments, alternating fishing days, joint searches/assessments of fish stocks and joint ownership of vessels and fishing gear.

2 The fishing rights apply only to coastal fisheries; offshore and high-sea fisheries are typically governed by a license system that is managed by either the central or the prefectural government. Also, there are three types of fishing rights-common, demarcated and large fixed net. For the context of this paper, common fishing right is the only relevant one.

3 This is referred to as privilege condition in the club theory literature (Sandler, 1992). 
Consider, for example, the fishing ground rotation. In white shrimp fishery, an FMO implemented a daily fishing ground rotation scheme (Platteau and Seki, 2001). FMO members and known fishing grounds were grouped into three, each FMO group is assigned to one fishing ground and they rotated daily when they went out fishing. If the group size is appropriately determined congestion in each fishing ground will be mitigated, if not eliminated and because there is no need to compete for better fishing grounds there is considerably low incentive to race to fish. Cost savings can come from slower steaming speed that increases fuel efficiency and less damage on fishing gear due to less congestion.

In small pink shrimp fishery fishing grounds are not rotated but assigned by the "fishing committee" that meets every day during the season (Uchida and Baba, 2008). This shrimp is a small zooplankton-like species that concentrates each evening as they rise near the surface, but the location where the clumps appear is highly variable. Rigid rotation system may be ill-suited in such condition because while one group might find near-empty ground another group might find overwhelming amount of shrimp. In fact, it often happens that some vessels with large catch radio the leader for help. The leader will then direct vessels with low catch to relocate and help haul the harvest or make additional tows nearby. Location assignment system allows such flexibility to be in place.

Effort coordination is not only applicable to the production operations; collective marketing is potentially an effective way to increase revenue and it is becoming increasingly popular among FMOs. Often seen is the development of private brand that is as simple as being explicit about the geographical origin (e.g., Maine lobster, Alaskan salmon). Others, particularly the successful ones, involve more coordinated effort in quality control and targeted marketing.

A pooling arrangement is an agreement among FMO members by which harvests, revenues and/or profits are pooled and then distributed back to members. ${ }^{4}$ The redistribution rule is either uniform (all participating fishing units receive the same amount) or weighted by indicators such as vessel size and number of crew members. Pooling arrangement is typically characterized as a supporting mechanism for effort coordination (Platteau and Seki, 2001). This is because, in essence, effort coordination is a restriction of individual's decisions and the differentials in harvest levels resulting from effort coordination must be addressed and adjusted (Uchida, 2009). A pooling arrangement is a method for handling this differential problem.

It is important to recognize, however, the importance of the fact that pooling arrangement breaks the link between the individual fishing effort applied and actual earnings received. This dampens the incentive to compete aggressively, which is favorable in light of the excessive fishing effort that is applied in the absence of comanagement. It also aligns the incentive of individual fishermen to that of a group; individual return is maximized

4 Pooling arrangements considered here do not include insurance purposes, as in risk pooling, since such fishery insurance is already offered by FCAs. 
only when the group's total return is maximized. This implies, for example, that it becomes an individual's own interest to avoid flooding the market and depressing the market price, which would lead to voluntary restraining of harvests. However, a pooling arrangement is a double-edged sword: if the incentive-dampening effect goes too far, shirking problems can undermine the FMO's stability. Number of case studies show that FMOs with pooling arrangements are functioning reasonably well (Hasegawa, 1985; Baba, 1991; Platteau and Seki, 2001; Gaspart and Seki, 2003; Uchida and Baba, 2008; Uchida and Watanobe, 2008). That said, the higher economic return from comanagement, particularly when that management includes a pooling arrangement, is critical in sustaining the comanagement regime.

Not all FMOs have effort coordination or pooling arrangement. According to the fishery census, about $12 \%$ of FMOs have pooling arrangement (MAFF, 2006). While the data on effort coordination per se is not included in the census, one indicative data is that approximately $50 \%$ of FMOs have joint marketing program of one form or another. These facts raise a question of what characteristics of FMOs might be influencing their decision to implement effort coordination and pooling arrangement. Using the survey data collected by the author this paper will analyze and identify those characteristics.

\section{Data}

Since there were no readily available datasets investigating effort coordination in the detail that we required, a mail survey was developed and implemented. The survey was targeted at FMO managers nationwide and was implemented in 2005 following the Dillman method (Dillman, 1978). The survey was pre-tested and then mailed out in late 2005.5

One of the first challenges in conducting the mail survey was to identify which FMOs to send the survey. Ideally we would want to send the survey to all FMOs nationwide, but it became apparent that this was not possible. The main complication is that there exists no single source of contact information for all of Japan's FMOs, primarily due to the fact that FMOs are typically autonomous organizations (Makino and Matsuda, 2005). An option was to send the survey to all fishery cooperatives (FCAs) for which contact information is available. However, there are many cases where two or more FMOs are formed within a single fishery cooperative and we were advised that a survey sent to a

5 Our survey was not the first one to be conducted on FMOs or on effort coordination. For example, in 1997 there was a survey conducted under the supervision of the Fishery Agency of the Japanese government. That survey was sent to regional government officers associated with FMOs located within various jurisdictions, who then answered the survey on behalf of FMOs. Our survey differs from the previous ones in two important ways: i) our survey was sent directly to FMO managers instead of government officials who oversee them and ii) questions were focused in great detail on effort coordination, pooling arrangements and other self-imposed regulations and fishing operations in general. 
generic recipient (i.e., not to specific FMOs) would tend to get less or no attention. For these reasons it became clear that we needed to have a list of specific contact information of FMOs, which led us to utilize the list of FMOs from a prior survey conducted in 1997 (see footnote 4). 386 surveys were sent out and 113 usable responses were received.

We defined "effort coordination" as i) fishing grounds rotation or location assignments and/or ii) exchanging information on fishing grounds. Table 1 shows the number of FMOs in our sample identified by the combination of effort coordination and pooling arrangements employed. There are significant numbers of FMOs with either effort coordination (Type B) or pooling arrangements (Type C) alone. This suggests that these arrangements are probably not simply transitional or exceptional institutions. Having both effort coordination and pooling arrangements as a pair (Type A) is not necessarily a norm and the question becomes whether there is a significant benefit of having both. Type D is defined as FMOs without either of the two effort coordination or pooling arrangements.

Table 1. Number of surveyed FMOs by their type

\begin{tabular}{c|c|c|c}
\hline Type & Effort coordination & Pooling arrangement & Count \\
\hline A & $\mathrm{x}$ & $\mathrm{x}$ & 38 \\
\hline B & $\mathrm{x}$ & $\mathrm{x}$ & 28 \\
\hline C & & & 18 \\
\hline D & & & 29 \\
\hline Total & & 113 \\
\hline
\end{tabular}

Notes: Count is the number of FMOs of respective types in the survey sample.

Our primary interest is determining how various combinations of effort coordination and pooling arrangement affect some economic performance measure. We focus on the revenue per unit of effort, which is defined as the revenue from the managed fisheries per member per fishing hour. The overall unconditional mean of revenue per unit of effort in our sample was 94.9 thousand yen (about \$860) with significant variance among the FMO-types ranging from 160.3 thousand yen $(\$ 1,500)$ for Type A to 4.3 thousand yen (\$40) for Type D (Table 2). Note that these figures are gross revenues before subtracting any expenses such as vessel maintenance, wages for crew and usage fees for shore-side facilities. Nevertheless, from these summary statistics alone, there seems to be a good reason to believe that FMOs with effort coordination and pooling arrangements have higher revenue per unit of effort than FMOs without these arrangements. Indeed, simple -tests among the means indicate that the Type A FMOs' performance measure is statistically different from Type B and D, but not so from Type C. Type B FMOs' revenues per fisherman day was statistically significant only from Type D, while that was not the case between Type C and Type D. This is weakly suggestive of the notion that effort coordination and pooling arrangements are more productive when implemented together. However, we would need to control for other factors affecting the revenue level to be more confident in this claim. 
Table 2. Descriptive statistics of survey sample data

\begin{tabular}{|c|c|c|c|c|}
\hline \multirow{2}{*}{ Variables } & \multicolumn{4}{|c|}{ FMO Type } \\
\hline & A & B & C & $\mathrm{D}$ \\
\hline Average membership size & 49.8 & 48.1 & 28.4 & 73.7 \\
\hline Average members age & 55.6 & 59.6 & 59.7 & 59.4 \\
\hline Average years of experience & 31.6 & 34.2 & 32.6 & 30.5 \\
\hline Average number of vessels registered & 35.4 & 39.7 & 26.2 & 84.7 \\
\hline Average number of vessels in operation & 15.4 & 19.9 & 21.9 & 29.1 \\
\hline Average vessel tonnage & 9.2 & 3.7 & 3.8 & 6.1 \\
\hline Average per member revenue & 9,833 & 5,337 & 5,388 & 3,027 \\
\hline Average number of fishing days per year & 66.0 & 118.9 & 92.6 & 120.2 \\
\hline Average fishing hours per day & 5.3 & 5.0 & 4.6 & 10.6 \\
\hline Revenue per fishing effort & 102.1 & 10.4 & 12.6 & 3.7 \\
\hline Fishing ground within TURF (\% of "yes") & 87.8 & 85.2 & 80.0 & 85.7 \\
\hline Solely owned TURF (\% of "yes") & 66.7 & 43.5 & 62.5 & 58.8 \\
\hline Type of managed targeted species: pelagic & 0.0 & 6.9 & 8.3 & 12.5 \\
\hline Groundfish & 14.0 & 20.7 & 8.3 & 4.2 \\
\hline Crustacean & 23.2 & 31.0 & 25.0 & 12.5 \\
\hline Sedentary & 62.8 & 41.4 & 58.3 & 70.8 \\
\hline
\end{tabular}

Notes: Monetary unit is in thousand Japanese yen.

One of the distinctive differences among FMO-types is the number of fishing days per year. Most notably, Type A FMO members spend far less time fishing than Type B or Type D FMO members. Table 2 seem to suggest that FMOs with pooling arrangements (Type A and C) tend to fish fewer days than the other two types. This is intuitive, since under the pooling arrangement there is less incentive to go out fishing in bad weather, for example, in comparison with behavior under individualistic competition. On the other hand, members of Type B FMOs are not under the environment of individualistic competition, but their numbers of fishing days are the same level as Type D FMOs. A possible explanation for this result is the "fairness adjustments" in response to effort coordination. With effort coordination such adjustments must be made, such as by providing equal chances of fishing at any given fishing ground to a vessel in a season (as observed in walleye pollack fishery in northern Japan; see Uchida and Watanobe, 2008 for details). This equity constraint may translate to maintaining a certain minimum days of fishing per year since it is easier to make such adjustments with more fishing days

Fishing hours per fishing day are not much different across FMO-types except Type D, which on average exhibits much longer fishing hours per day. This suggests that fishing effort may be more concentrated, presumably around the most profitable times, in Type A and perhaps Type C FMOs.

If Type A FMOs are earning higher revenue per unit of effort, one might expect that, ceteris paribus, i) membership size of these FMOs are smaller than other types (e.g., Agrawal, 2001) and ii) FMOs would successfully attract younger generation (i.e., successors) 
to the fishery. Regarding the first point, Type A through Type C FMOs have smaller membership sizes than Type D, but Type A is certainly not the smallest. The average age of FMO members is lower for Type A but not significantly so and the same is true for average years of experience as a fisherman. Thus, the two hypotheses above are not supported by our sample.

According to the literature such as Ostrom et al. (2002), self governance has better chance of success if the managed resource is sedentary. Our survey sample shows the consistent trend, where the majority of FMOs of all types manage sedentary species. Furthermore, it is interesting that none of the Type A FMOs manage pelagic fish species, which is considered to be the least suitable for resource self governance. The high share of crustacean species could be the effect of their higher value in general; species such as spiny lobster and many types of crabs tend to fetch higher price in the market. High valued species could provide an extra incentive to manage well so as to sustain the fishery.

\section{Empirical model}

We are interested in whether there are any systematic differences between the revenue per unit of effort (rpue) and the FMO-types. Our objective is to determine how much we can attribute this variation to the difference in management regimes.

Simply establishing a TURF-based fishery cooperative does not eliminate the incentive to race to fish (Uchida, 2004). New entries will be limited but, if nothing else is done, the race among the incumbents will prevail, leading to a waste of capital, low profitability and overall depletion of the resource and economic rents. The simple establishment of an FMO will not be much different either, unless other actions are taken by FMO members. With an FMO, the authority of fishery management devolves from the officials to the local fishermen. This decentralization may improve the level of compliance, but since underlying incentives to race for fish are unaffected without additional measures, the impact of such a regime shift on economic outcomes is likely to be limited.

We hypothesized that FMOs with effort coordination and/or pooling arrangements (Type A, B, or C) will have higher revenue per unit of effort than those without such arrangements implemented (Type D). Successful fishery comanagement requires that a restricted group be granted rights to the resource. This is what establishment of the TURF provides. But successful comanagement also requires that the restricted group that has been granted rights can successfully overcome internal organization costs and collectively exercise policies that manage the resource sustainably and profitably. Effort coordination is an active management measure that may be used to fulfill this requirement. Pooling arrangements, in contrast, can be thought of as passive measures in the sense that they do not require fishermen to continuously decide on terms of operation. However, pooling arrangements 
alter the incentive structures in such a way that, if implemented appropriately, individual incentives are aligned with that of a group as a whole. This is because maximizing the total benefit of a group, i.e., the whole "pie", will also maximize one's individual dividend under the pooling arrangement.

We would also expect that FMOs with both effort coordination and pooling arrangements (Type A) to exhibit higher revenues per unit of effort than those with only either one (Type B or C). Effort coordination deals with the allocation of inputs of harvesting operation, while pooling arrangements deal with the allocation of outputs among the FMO members. Intuitively, coordinating and pooling complement each other and we would expect FMOs with both to be more efficient and effective.

The following simple regression was conducted to check quantitatively whether the FMO-types matter at all. The model is

$$
\ln r p u e_{i}=\alpha+\beta_{1} \text { Type_A}_{i}+\beta_{2} \text { Type_B } B_{i}+\beta_{3} \text { Type_ } C_{i}+\varepsilon_{i} \text {, }
$$

where Type_A through Type_C are as defined in Table 1 and $\varepsilon i$ is the error term. The subscript $\mathrm{i}$ denotes an FMO. Note that the Type D FMO variable is excluded from the estimation. The result from heteroskedasticity-robust OLS shows that Type A and Type B FMOs have significantly higher revenue per unit of effort than Type D FMOs (Table 3). Thus, it seems suggestive at this junction that FMO-types do have influence over the revenue per unit of effort; the next step is to control for other covariates that affect revenue per unit of effort.

Other influential factors that may impact revenues per unit of effort need to be controlled for. These include targeted species-type, product-type (which product markets the harvest is allocated to) and the vessel size. In addition, membership size of an FMO might also be an influencing factor. Literature on commons and collective action often claim that smaller groups have better chances for successful collective action, in terms of sustainability and performance (Agrawal, 2001). Therefore, smaller FMOs might have higher revenue per unit of effort, ceteris paribus. Lastly, there could be a learning effect.

Table 3. Heteroskedasticity-robust OLS with only FMO-type variables

\begin{tabular}{c|c}
\hline Variable & Coefficient \\
\hline Type A & $1.813(4.70)^{\star * *}$ \\
\hline Type B & $0.711(1.97)^{*}$ \\
\hline Type C & $0.781(1.34)$ \\
\hline Constant & $-1.324(5.17)^{\star * *}$ \\
\hline Adjusted $\mathrm{R}^{2}$ & 0.165 \\
\hline
\end{tabular}

Notes: Absolute t-values in parentheses. Number of observations in this regression is 72 . *** significant at $1 \%,{ }^{* *} 5 \%$ and * $10 \%$. 
The hypothesis is that the longer an FMO endures, the better it is in management performance. This is a plausible hypothesis given anecdotal evidence of actual cases where FMOs often modify and fine-tune their management practices over time (Uchida, 2004).

\subsection{Targeted species-types}

It is common knowledge that certain harvested species command higher prices than other species in general. In Japan, for example, spiny lobsters and certain species of crabs (e.g., snow crabs) are generally considered high-end or luxury foods and thus are traded at higher prices. Thus, we would need to control for FMOs' main targeted species.

One needs to be cautious in including the species-type variables into the model. If the case was such that high-value species are caught dominantly by Type A FMOs and low-value species are caught dominantly by Type D FMOs, or vice versa, then including both FMO-type and species-type variables will cause serious multicollinearity problems. To see if this problem exists in our sample, we counted the number of FMOs by targeted species and by FMO-types. There were total of 66 species targeted in our sample, with most of them having only three or fewer FMOs involved. Our focus is the "popular" targeted species and thus we separated species with seven or more FMOs involved. Also, since abalone and turban shell were often harvested as a pair of targeted species, these two were treated as one species entry. The results showed that there are no systematic correlations between FMO-type and species-type variables and hence we include the species-type variables into the model.

\subsection{Product-types}

The revenue level can potentially be influenced by the market-types to which harvested fish are sold. Fish designated to fresh markets generally fetch higher prices than those going to frozen or processed markets. Freshness is of particular importance for Japanese consumers as there is substantial demand for raw consumption of fish. Whether that translates into higher revenue, however, is an empirical question. Nonetheless, implementing rigorous quality control measures so as to allocate their harvest to raw and fresh consumption is a popular practice that FMOs engage in. This is in line with the claim that benefit of rationalized fishery management coming from output markets in terms of increased price is substantial and critical in sustaining the regime (Homans and Wilen, 2005; Herrmann, 1996).

We will denote the different markets which harvest is designated to as "producttype." First we divided the product-type into two categories: domestic consumption, including both final and intermediate and exports. 6 Domestic consumption was further sub-categorized into raw, fresh, processed and feed. The first two are for final consumption. 
It is not uncommon that a single species is allocated to multiple markets. For this reason, the survey asked the respondents to give the share of each product-type. Overall, the majority of harvests go to either raw or fresh markets, with average of $27.7 \%$ going to the raw market and $56.9 \%$ to the fresh market.

\subsection{Gear-types}

Another factor that might affect the revenue level is the harvest method employed, particularly within a single species-type. Controlling for gear-type is clearly necessary if there are multiple gear-types employed for the same targeted species and that there is a reason to believe that might have an impact on revenue level. We examined the top two gear-types used to harvest the popular targeted species. ${ }^{7}$ Results showed that the issue of multiple gear-types in a single species is quite limited. With an exception of turban shell, all other species are harvested by single gear-types across different FMOs. As for turban shell, since it is often combined with the abalone fishery, diving can be considered as the dominant harvesting method for the two species. From these results, we conclude that including both species-type and gear-types variables will likely to cause multicollinearity problems, thus gear-type variables were excluded from the estimation models.

\subsection{Other variables}

There are other variables that can potentially be included in the model. An obvious one is the average tonnage of vessels. This is the average tonnage of vessels owned by FMO members and it is intended to be a proxy for crew member size. Intuitively, larger crew sizes bring higher revenues for an FMO member, who is typically a vessel owner and skipper, per fishing hour. Since we do not have the crew size variable, we include the average tonnage of vessels based on the assumption that typically larger vessels have more crew members on board.

A few more variables are considered primarily in response to the possible issue of endogeneity. Specifically, we are concerned about any omitted variables that not only affect the level of per member revenue but also the likelihood of a group choosing a particular FMO type. ${ }^{8}$ One of such variable is the FMO's membership size. As Ostrom (1990)

6 According to the fisheries white paper, during the 2004 fiscal year the domestic fishery production was 1,604 billion yen, of which 148 billion yen or 9.2\% was exported (Fishery Agency, 2005).

7 First we tried to count the top three gear-types, but turned out that there was no third popular gear-type in our sample.

8 We do not have a selection bias issue here; we have observations on revenue for all four types of FMOs and we know exactly which revenue data belongs to which FMO-type. Also, since our sample is confined within FMOs we cannot address the question of what factors determine the establishment of FMOs. 
and others have pointed out, smaller groups have better chance of implementing collective action and perhaps more sophisticated forms of collective action than larger groups, ceteris paribus. This suggests that group size affects the choice of FMO types; smaller groups tend toward being Type A.

In addition to membership size, we considered the FMOs' established year index variable. This variable range from 1 to 11 , each corresponding to an interval of five years where 1 is the oldest (established on year 1935 and prior) and 11 is the most recent (established year, 2001 and after). 8 The question is whether any learning effect is present or not. Also, it is often the case that FMOs modify and in many cases fine-tune their management schemes and rules over time. We would expect that such modifications take place in aim to increase the return from the fishery, because making such changes incur cost.

\subsection{Model specification}

All of the aforementioned covariates were considered to be included in our empirical model. It was revealed, however, that inclusion of both species-type and product-type variables exhibited a typical sign of multicollinearity: high adjusted $\mathrm{R}^{2}$, a significant F-test and non-significant t-tests of coefficients. We thus conclude that species-type and product-type variables should not be included together in our estimation model. Upon comparing the models with species-type and product-type variables, it was determined to retain the species-type variables in our empirical model.

We also considered specifications such as double-log (replacing tonnage, membership size and years variables with the logarithm of respective variables) and inclusion of squared terms for tonnage, membership size and years variables. Furthermore, interaction terms of FMO types and tonnage, membership size and years variables were considered to examine whether the effects of these variables differ across FMO types. The goodness of fit of these models were compared based on the F-values and adjusted $\mathrm{R}^{2}$. In conclusion, our basic empirical model is

$$
\begin{aligned}
\ln \text { rpue }_{i}=\alpha & +\sum_{j} \beta_{j} \text { type }_{i j}+\sum_{k} \beta_{k} \text { species }_{i k}+v_{1} \text { tonnage }_{i}+v_{2} \text { membersize }_{i}+v_{3} \text { years }_{i} \\
& \sum_{j} \gamma_{j}\left(\text { type }_{i j} \times \text { tonnage }_{i}\right)+\sum_{j} \delta_{j}\left(\text { type }_{i j} \times \text { membersize }_{i}\right)+\sum_{j} \eta_{j}\left(\text { type }_{i j} \times \text { years }_{i}\right)+\varepsilon_{i}{ }^{\prime}
\end{aligned}
$$

where subscript $\mathrm{i}$ denotes an $\mathrm{FMO}, j=\{A, B, C\}$ and $k$ is a vector of species-type as listed in Table 4. Regression diagnostics were performed to detect any influential outliers in our sample but none among the 67 observations was found; details are explained in the appendix. 


\section{Regression results}

\subsection{FMO types}

The coefficient estimate of the Type A FMO variable is 1.19 and it is statistically significant at $1 \%$ level (Table 4). Since only the dependent variable is in a natural log form, the interpretation of coefficients is the percentage change in revenue per unit of effort in response to a unit change in explanatory variables. Thus, it is estimated that a member of Type A FMOs earn approximately $118 \%$ more revenue per unit of effort than

Table 4. Heteroskedastic-robust OLS model with RPUE as dependent variable

\begin{tabular}{|c|c|c|}
\hline Variables & & Estimated Coefficient \\
\hline \multirow{3}{*}{ FMO type $^{a}$} & Type A & $1.189(2.247)^{\star \star \star}$ \\
\hline & Type B & $0.425(0.456)$ \\
\hline & Type C & $1.961(1.703)^{\star}$ \\
\hline \multirow{7}{*}{ Species type ${ }^{b}$} & Spiny lobster & $0.097(0.143)$ \\
\hline & Abalone and turban shell & $-0.315(0.767)$ \\
\hline & Scallop & $1.756(5.927)^{\star * *}$ \\
\hline & Asari-clam & $-0.412(0.534)$ \\
\hline & Other migratory fish & $-0.479(1.441)$ \\
\hline & Other non-migratory fish & $2.250(3.937)^{\star * *}$ \\
\hline & Other sedentary species & $1.927(4.428)^{\star * *}$ \\
\hline \multicolumn{2}{|l|}{ FMO membership size } & $-0.00002(0.003)$ \\
\hline \multicolumn{2}{|l|}{ Average vessel tonnage } & $0.155(2.506)^{\star \star}$ \\
\hline \multicolumn{2}{|l|}{ Years since FMO establishment } & $0.0203(0.212)$ \\
\hline \multicolumn{2}{|l|}{ Type A x membership size } & $-0.003(0.331)$ \\
\hline \multicolumn{2}{|l|}{ Type A $x$ tonnage } & $-0.166(2.684)^{\star * \star}$ \\
\hline \multicolumn{2}{|l|}{ Type A x years } & $-0.071(0.563)$ \\
\hline \multicolumn{2}{|l|}{ Type B x membership size } & $0.028(2.600)^{\star *}$ \\
\hline \multicolumn{2}{|l|}{ Type B $x$ tonnage } & $-0.018(0.206)$ \\
\hline \multicolumn{2}{|l|}{ Type B x years } & $-0.285(1.959)^{*}$ \\
\hline \multicolumn{2}{|l|}{ Type C x membership size } & $0.017(1.511)$ \\
\hline \multicolumn{2}{|l|}{ Type $\mathrm{C} \times$ tonnage } & $-0.998(7.473)^{\star * *}$ \\
\hline \multicolumn{2}{|l|}{ Type C x years } & $-0.003(0.020)$ \\
\hline \multicolumn{2}{|l|}{ Constant } & $-1.797(3.554)^{\star * \star}$ \\
\hline \multicolumn{2}{|l|}{ Adjusted $\mathrm{R}^{2}$} & 0.549 \\
\hline \multicolumn{2}{|l|}{ Number of observations } & 67 \\
\hline
\end{tabular}


the Type D FMO members. This is within the plausible range based on the result from the descriptive statistics (Table 2). The model also estimates that Type A FMO members earns significantly, in a statistical sense, higher revenue per unit of effort than Type B FMO member at 5\% significance level. Such was not the case, however, between Type $A$ and Type C. In addition, estimated coefficients of Type B and Type C were not significantly different from each other.

The results show that Type A and Type C FMO members earn significantly higher revenue per unit of effort compared to Type D FMO members, with much stronger significance for Type A FMOs. This suggests that (1) combining effort coordination and pooling arrangement has super-additive impact on revenue per unit of effort, while (2) effort coordination or pooling arrangement alone has no or only marginal impacts on the revenue per unit of effort.

We hypothesized that FMOs with either effort coordination or pooling arrangements perform better than those without either of the two schemes. This is partly supported by the fact that estimated coefficients for Type B and Type $\mathrm{C}$ were positive, but not fully supported since Type B was statistically insignificant. Our second hypothesis that FMOs with both measures perform better than those only with only either one was almost fully supported, as the coefficient for Type A was estimated to be highly significantly different from Type D. We say "almost" because (1) Type C was also statistically significant, albeit at only $10 \%$ level and (2) the t-test among the coefficients of three FMO types revealed that none were statistically superior over the other, although Type A was almost significantly different from Type B with the p-value of 0.112 .

The result that there is no significant difference in revenues per unit of effort between Type A and Type C FMOs raises an interesting question as to how exactly Type C FMOs operate. If the revenue is pooled but without established central decision-making mechanisms (such as committees), how does each individual fisherman in Type C FMOs operate? For example, do they operate the same way spatially (i.e., in choosing fishing grounds) but simply less intensively? An interview with one Type C FMO manager provides hints about answers to these questions. This particular FMO harvests surf clams and the purpose of employing the pooling arrangement was to mitigate the members' incentive to race to fish. On each fishing day, revenue is shared only among the members who participate in fishing; those who stay on shore are excluded. This eliminates the incentive to free-ride by staying on shore. Also, in this fishery there are several fishing grounds that are distant from their port, but nonetheless need to be cultivated. With the pooling arrangement in place, no individuals have the incentives to fish in these grounds since fishing costs are not shared. There are no explicit rules as to how to take turns to harvest these fishing grounds, but there is an implicit rule-of-thumb that if you operate in nearby fishing grounds for three days you would go to more distant grounds for a day. If a member is caught not following this implicit rule, based on peer monitoring, this member will be 
penalized in the form of reduced share of pooled revenue. In essence, this Type C FMO has implicit effort coordination in place. We have no method to verify if this is the norm for any of the surveyed Type C FMOs. If it is, however, then the distinction between Type $\mathrm{A}$ and Type $\mathrm{C}$ becomes vague and this would explain why we do not detect significant differences in revenue levels between these two FMO types.

A few observations on the interaction terms are worth mentioning. For Type A FMOs it turns out that none of the three attribute variables?membership size, tonnage and years since establishment?matters for the members' revenue per unit of effort. Note that the coefficients for average tonnage $(0.155)$ and that interacted with Type A $(-0.166)$, both statistically significant, cancel out. Similar outcome is observed for tonnage variable interacted with Type C (-0.998). An interesting result is that the membership size was positive and significant for Type B FMOs. Given that the magnitude of fishing inefficiency increases with membership size (Cheung, 1970; Gordon, 1954), this in retrospect implies that effort coordination has the greatest impact on FMOs with larger membership size.

\subsection{Other self-imposed regulations}

Next we asked whether the combination of effort coordination and pooling arrangement is solely responsible for higher revenue per unit of effort. There are many other types of self-imposed regulations and measures that FMOs can employ and they indeed do so (Table 5). We categorized these self-imposed regulations as follows.

1. Marketing: quality control measures such as proper icing and careful release from nets, development of new value-added products and branding.

2. Harvest control: setting TAC and/or individual quota, control daily landing volume to avoid market glut and fish size and age restrictions.

3. Operation regulations: restrictions on fishing hours and days, seasonal closure, setting no-fishing zones and restrictions on fishing method, fishing gear and number of crew on a vessel.

4. Vessel regulations: restrictions on number of vessels, tonnage and engine power. Note that some of above regulations are also imposed by the local or central government but in the survey we explicitly asked for self-imposed regulations, including those are more stringent than existing government regulations.9

We first estimated whether these four categories of self-imposed regulations have any impact of their own on revenue per unit of effort (Model 1 in Table 6). Results show that none has a statistically significant impact. The estimated positive sign for the marketing variable is intuitive, as such activities are typically aimed to bring higher revenue. The negative sign for the harvest control variable is plausible if the market price did not respond enough to reduced landing volume to supplement the loss. 
Table 5. Number of FMOs by self-imposed regulations

\begin{tabular}{c|c|c|c|c|c}
\hline Regulations & Type A & Type B & Type C & Type D & Total \\
\hline Marketing & 27 & 10 & 4 & 5 & 46 \\
\hline Harvest control & 25 & 13 & 6 & 8 & 52 \\
\hline Operation regulations & 31 & 18 & 6 & 8 & 63 \\
\hline Vessel regulations & 18 & 4 & 2 & 2 & 26 \\
\hline
\end{tabular}

Note that the Type A FMO variable remained statistically significant even after the addition of self-imposed regulation covariates. Thus, the next question is whether the combinations of Type A FMOs and self-imposed regulations have significant impacts on revenue per unit of effort. To do so, we introduced the interaction terms of Type A and regulation variables. The model is

$$
\begin{aligned}
\ln \text { rpue }_{i}= & \alpha+\sum_{j} \beta_{j} \text { type }_{i j}+\sum_{k} \gamma_{k} \text { species }_{i k}+v_{1} \text { tonnage }_{i}+v_{2} \text { membersize }_{i}+v_{3} \text { years }_{i} \\
& \sum_{j} \gamma_{j}\left(\text { type }_{i j} \times \text { tonnage }_{i}\right)+\sum_{j} \delta_{j}\left(\text { type }_{i j} \times \text { membersize }_{i}\right)+\sum_{j} \eta_{j}\left(\text { type }_{i j} \times \text { years }_{i}\right) \\
& \sum_{l} \kappa_{l}\left(\text { TypeA }_{i} \times \text { regulations }_{i l}\right)+\varepsilon_{i}
\end{aligned}
$$

where regulations $s_{i l}$ denotes regulation l's dummy variables, which equals 1 if implemented by an FMO $i$.

The estimation results of equation (2) are shown as Model 1 in Table 6. Results show that marketing employed by Type A FMOs has positive and statistically significant impacts on revenue per unit of effort. This suggests that marketing practices is likely to be effective in increasing the revenue if they are conducted under the effort coordination supported by the pooling arrangement. On the other hand, we find that harvest controls have negative and significant impacts. Harvest control often involves curtailing the harvest volume, which could then lead to the reduction of total revenue.

In the next estimation model, both marketing and harvest control were divided into their subcategories to investigate which of these subcategories were most influential (Model 2 in Table 6). Marketing variables includes quality control, new product development and branding. Harvest control variables includes total catch limit (or TAC), individual catch limit (or IQ), supply/landing volume control and size/age restrictions. Each of these subcategories was interacted with Type A FMO dummy variable.

There are several interesting results from Model 2. Firstly, none of the marketing sub- categories were significant. A plausible explanation could be that the success of marketing depends heavily on the product-type and market conditions on case-by-case basis, thus no specific marketing activities can be a silver bullet. The result with the aggregated marketing variable in Model 1, in return, implies that Type A FMOs are engaged in different 
but most effective marketing activities given their market environment.

Table 6. Heteroskedasticity-robust OLS with interaction terms of Type A FMOs and other self-imposed regulations

\begin{tabular}{|c|c|c|c|}
\hline & \multirow{2}{*}{ Variables } & \multicolumn{2}{|c|}{ Estimated Coefficient } \\
\hline & & Model 1 & Model 2 \\
\hline \multirow{3}{*}{ FMO type $^{a}$} & Type A & $2.059(2.591)^{\star \star \star}$ & $1.697(1.847)^{*}$ \\
\hline & Type B & $0.561(0.599)$ & $-0.363(0.333)$ \\
\hline & Type C & $1.609(1.396)$ & $1.718(1.100)$ \\
\hline \multirow{7}{*}{ Species type ${ }^{b}$} & Spiny lobster & $0.141(0.193)$ & $0.459(0.649)$ \\
\hline & Abalone and turban shell & $0.223(0.501)$ & $-0.581(1.096)$ \\
\hline & Scallop & $1.954(5.833)^{\star * *}$ & $1.275(2.250)^{\star *}$ \\
\hline & Asari-clam & $0.161(0.232)$ & $-0.076(0.089)$ \\
\hline & Other migratory fish & $-0.248(0.620)$ & $-0.649(1.575)$ \\
\hline & Other non-migratory fish & $2.307(3.535)^{\star * *}$ & $1.575(2.643)^{\star *}$ \\
\hline & Other sedentary species & $2.063(3.801)^{\star \star \star}$ & $1.531(2.274)^{\star \star}$ \\
\hline \multicolumn{2}{|c|}{ FMO membership size } & $-0.003(0.319)$ & $-0.0001(0.011)$ \\
\hline \multicolumn{2}{|c|}{ Average vessel tonnage } & $0.184(3.030)^{\star * *}$ & $0.148(2.220)^{\star *}$ \\
\hline \multicolumn{2}{|c|}{ Years since FMO establishment } & $-0.017(0.170)$ & $-0.002(0.016)$ \\
\hline \multicolumn{2}{|c|}{ Type A x membership size } & $-0.003(0.385)$ & $-0.001(0.128)$ \\
\hline \multicolumn{2}{|c|}{ Type $A \times$ tonnage } & $-0.200(3.266)^{\star * *}$ & $-0.156(2.314)^{\star *}$ \\
\hline \multicolumn{2}{|c|}{ Type $A$ x years } & $-0.054(0.424)$ & $0.041(0.257)$ \\
\hline \multicolumn{2}{|c|}{ Type B $x$ membership size } & $0.030(2.780)$ & $0.024(2.189)^{\star *}$ \\
\hline \multicolumn{2}{|c|}{ Type $\mathrm{B} \times$ tonnage } & $-0.032(0.384)$ & $0.012(0.136)$ \\
\hline \multicolumn{2}{|c|}{ Type B x years } & $-0.272(1.937)^{*}$ & $-0.162(0.917)$ \\
\hline \multicolumn{2}{|c|}{ Type $\mathrm{C} \times$ membership size } & $0.017(1.607)$ & $0.017(1.295)$ \\
\hline \multicolumn{2}{|c|}{ Type $\mathrm{C} \times$ tonnage } & $-0.966(7.614)^{\star \star \star}$ & $-0.965(5.822)^{* * *}$ \\
\hline \multicolumn{2}{|c|}{ Type $\mathrm{C} \times$ years } & $0.037(0.262)$ & $0.029(0.150)$ \\
\hline \multicolumn{2}{|c|}{ Type A x marketing } & $1.224(2.104)^{\star *}$ & \\
\hline \multicolumn{2}{|c|}{ Type A x harvest control } & $-1.082(2.179)^{\star *}$ & \\
\hline \multicolumn{2}{|c|}{ Type $A \times$ operation regulations } & $-0.199(0.392)$ & \\
\hline \multicolumn{2}{|c|}{ Type $A x$ vessel regulations } & $0.448(1.064)$ & \\
\hline \multicolumn{2}{|c|}{ Type A x quality control } & & $-0.666(1.240)$ \\
\hline \multicolumn{2}{|c|}{ Type $A \times$ new product development } & & $0.964(1.364)$ \\
\hline \multicolumn{2}{|c|}{ Type A x branding products } & & $-0.605(1.167)$ \\
\hline \multicolumn{2}{|l|}{ Type A x TAC } & & $0.640(1.153)$ \\
\hline \multicolumn{2}{|c|}{ Type $A \times$ individual quota } & & $1.365(2.011)^{*}$ \\
\hline \multicolumn{2}{|c|}{ Type A x supply control } & & $-0.508(0.763)$ \\
\hline \multicolumn{2}{|c|}{ Type A x size/age control } & & $-0.811(1.659)$ \\
\hline Operation regu & ns & & $0.762(1.296)$ \\
\hline Vessel regulati & & & $-0.064(0.158)$ \\
\hline Constant & & $-1.995(3.372)^{\star * \star}$ & $-2.109(2.067)^{\star \star}$ \\
\hline Adjusted $\mathrm{R}^{2}$ & & 0.559 & 0.565 \\
\hline Number of obs & ations & 67 & 67 \\
\hline
\end{tabular}

Notes: ${ }^{a}$, Type D FMO is set as the base FMO-type.

', Surf clam is set as the base species-type.

Absolute $t$-valuesinparenthesis.Significancelevelsareindicatedby ${ }^{* * *}$ significantat $1 \%, 5 \%$,and $10 \%$. 
Secondly, results on harvest control subcategory variables show that individual quota (IQs) system has positive and significant impact on revenue per unit of effort. If the race to fish incentive prevailed prior to IQ being implemented, then with the IQ system the landing volume might have decreased, mitigating the flooding of the market and fetched higher price, leading to higher revenue per unit of effort. However, here we are examining the impact of these self-imposed regulations within the context of Type A FMOs, who has both effort coordination and pooling arrangements. Therefore, the incentive to race to fish is likely to be less intense, so this scenario is probably unlikely.

Alternative explanation is that IQs could be functioning as a "benchmark" to detect shirking members. Because of the presence of the pooling arrangement, FMO members are in principle prone to shirking. If a member returns from his fishing trip with a harvest volume far below his quota to an extent that it is beyond a reasonable daily fluctuations, that could be used as an indicator that he might have been shirking out in the sea. IQs can be used to replace physical peer monitoring among the members, which can be useful in fisheries where vessels are operating in a dispersed manner.

\section{Conclusions}

Using the survey data collected directly from a sample of FMO managers across Japan, we investigated whether FMOs with fishing effort coordination and pooling arrangements perform better than those without these management arrangements. Theoretically, effort coordination will convert the fishing operation from individualistic competition under the limited access environment to more sole owner-like operation. Pooling arrangements alter the incentives such that individual incentives are aligned with the group incentive, thereby further enhancing the possibility of sound and sustainable collective fishery management. However, whether and how that translates to higher economic returns, such as increased revenue, is an empirical question.

We estimate that a member of Type A FMOs (both effort coordination and pooling arrangement) earn significantly higher revenue per unit of effort than a member of Type D FMOs (none of the two implemented). Furthermore, in Model 1 Type C FMO (only pooling arrangement) members also earn higher revenues per unit of effort than Type D FMO members; such was not true for Type B FMO members (only with effort coordination). Although this might seem to suggest that pooling arrangements have larger influences on revenue than effort coordination, Type $\mathrm{B}$ and Type $\mathrm{C}$ were not significantly different from each other and Type $\mathrm{C}$ became insignificant in subsequent estimation models. Thus, our hypothesis that FMOs with either effort coordination or pooling arrangement perform better 
than those without the two arrangements was not fully supported. However, the data supports our second hypothesis that FMOs with both perform better than those with only either one.

As a policy implication, does our result indicate that effort coordination and pooling arrangement are the essential ingredients, particularly so when put together, for successful fishery comanagement? We believe that is the case to a certain extent, but there are other conditions that are essential. In particular, effort coordination and pooling arrangements are still frameworks to act within their institutions and the question remains as to what actions do FMO members take with coordinated effort supported by pooling arrangements.

One answer this study suggests is that active-and well-coordinated?marketing activities enhance revenues in Type A FMOs. There are several ways to do this depending on the market conditions which the industries/communities face. If the fish they catch is well known by consumers (e.g., salmon) then an effective marketing strategy could be to pursue stringent quality control with the aim of differentiating locally caught fish in the market from those caught elsewhere. On the other hand, if the product itself is not well known in designated markets (e.g., Chilean sea bass a few years back) then promotion marketing can be effective. Taking this one step further, one might be able to create a new market by introducing new products. If these activities are sought in fisheries that are dominated by small-scale fishers, as was the case in most of the Japanese coastal fisheries, then they need to be carried out collectively to be effective. Thus, effort coordination and pooling arrangements become essential and complementary institutional frameworks.

Note that the dependent variable of our model was revenue per unit of effort, which was defined as revenue per FMO member per fishing hour. This means that even if the revenue per unit of effort is high, one's total (or annual) revenue level can still be low, or not enough to support a livelihood throughout the entire year. Effort coordination, particularly rotating fishing grounds and days, could mean that your turn to go out fishing comes only once in a while. Pooling arrangements will discourage one to go fishing under uncomfortable conditions, such as in bad weather. All of these result in fewer fishing days. Indeed, according to Table 2, the number of fishing days per year was much smaller for Type A, followed by Type C FMOs.

The possibility of fisheries being lucrative but unable to bring enough total revenues to support the livelihood of fishermen means that income from outside the managed fisheries can be critical for successful and sustainable fishery comanagement. This point was raised by many FMO managers and local researchers we interviewed. Such outside income sources include fisheries other than the managed ones, farming and non-primal industries sector jobs such as construction work.

This is not, of course, necessarily always the case. Like the case of the Pacific halibut fishery, a fishery management policy that reduces the race to fish and redirects more effort to quality control can achieve both a more lucrative fishery and a prolonged fishing season. In such a case, the availability of outside income sources might not be 
of significant importance. The conclusion of this paper is thus that effort coordination and pooling arrangements may not be the most important, but certainly may be one of the important factors for successful fishery comanagement.

\section{Acknowledgement}

The author would like to thank Dr. Osamu Baba and National Federation of Fisheries Cooperative Associations (JF Zengyoren) for their assistance in developing and mailing the survey, and two anonymous referees for their comments. Any errors are the sole responsibility of the author. 


\section{Appendix: Regression diagnostics}

One of the issues with mail survey is that the researcher does not have a full control on how the respondents respond to the questions, as opposed to face-to-face interviews. We made every effort to make important aspects of our questions explicit and comprehensible with wording and layout of the survey itself. Nonetheless, we still need to pay attention to possible measurement error of the data. As such, we devoted much time cleaning and checking the data for apparent inconsistencies. Beyond that there is little we can do without resorting to ad hoc methods, which is inappropriate. However, one would want to avoid the situation where small numbers of erroneous but undetected data outliers dominate the model estimates and predictions. For this reason we conducted a set of regression diagnostics to detect influential observations and outliers. The strategy we pursued was to look for such observations and then take closer looks at the data points to determine whether they are legitimately occurring outliers or erroneous data.

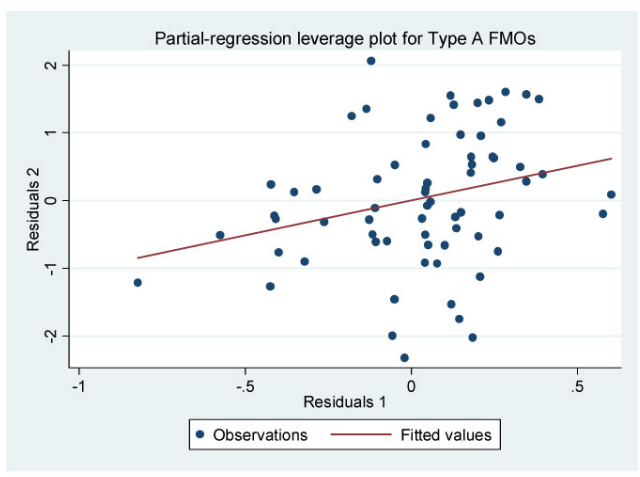

(a) Type A

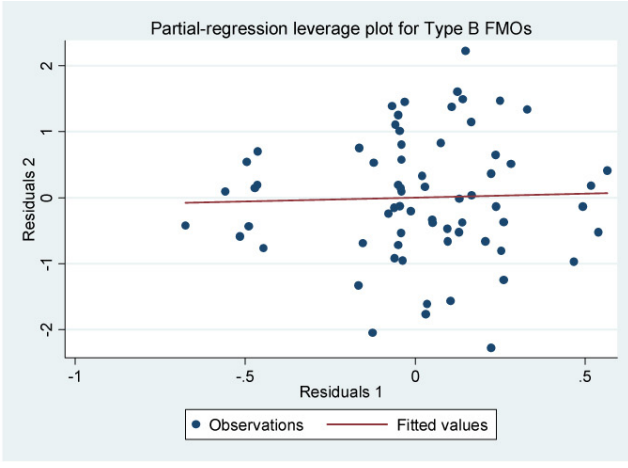

(b) Type B

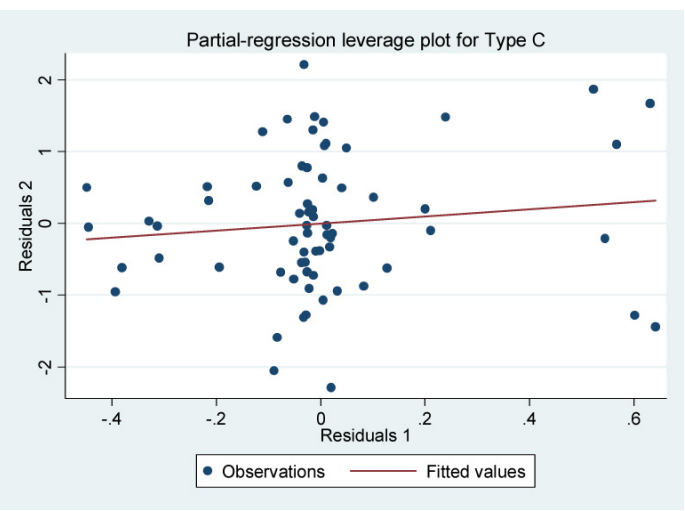

(c) Type C

Figure 1. Partial regression leverage plots for variables Type A, B and Type C 
Following Belsley, Kuh and Welsch (1980), we conducted diagnostics on two main issues: i) influential observations on estimated coefficients (the slope of fitted curve) and ii) normality assumption of the error term. For the first diagnostic, since the variables of our primary interest are FMO-types (A, B and C) we examined if there are any observations influencing disproportionately the estimated coefficients of these variables.

Partial regression leverage plots, which visually show the influential observations, are presented in Figure 1. The slope of fitted line represents the estimated coefficient for the respective variables. In panel $b$ there are no apparent observations suspected of disproportionately influencing the slope of the fitted line. In panel a, an observation to the far left is suspected of pulling down the fitted line on that end, thus creating a significant and positive slope. In panel c, a data point at upper right-hand corner could be pooling up the fitted line on that end, thus creating a significant and positive slope. However, DFBETA statistics, which gives numerical values of an observation's influence on estimated coefficients, indicates that these particular observations were below the threshold level (i.e., the null hypothesis that this observation is not influential was not rejected). In fact, there was no incident where DFBETA statistics were above the threshold, thus none of the 67 observations in our model was statistically influential. The possibility of the existence of multivariate outliers were also tested and rejected.

The results from partial regression leverage plots and other statistics such as DFBETA suggest that there is no influential outlier in the regression sample, but clearly this does not imply that the data is error-free. However, with 67 observations-not large but certainly not small in statistical sense-we can assume that any bias will on average cancel out.

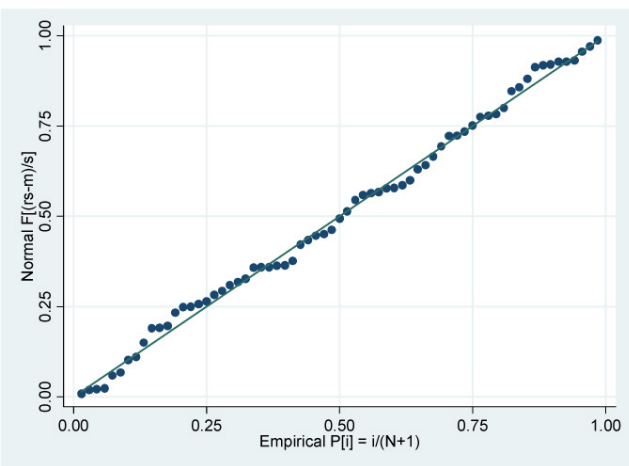

(a) $n=67$

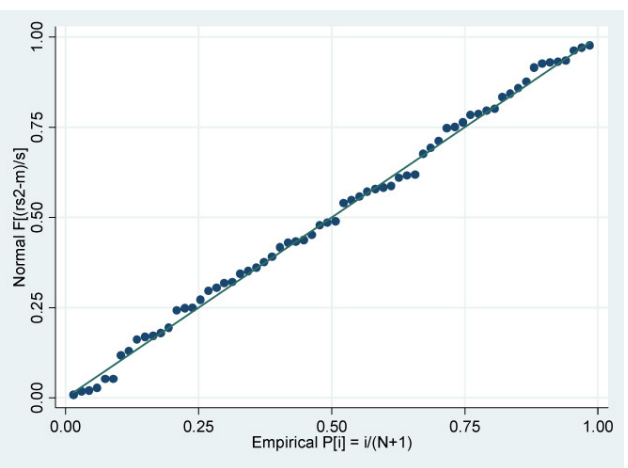

(b) $n=66$

Figure 2. Normal probability plot

Normality assumptions of the error term in the model and thus the regression residuals, are critical in making inference of the regression results. A moderate departure from normality can impair estimation efficiency and the meaningfulness of standard hypoth- 
esis tests. A commonly used method to detect such departures from normality is the normal probability plot, where observed cumulative probabilities of occurrence of the standardized residuals are plotted against the expected normal cumulative probabilities of occurrence. If the regression residuals are truly distributed normally, then the result will be the 45-degree line. Thus, departure from this line will indicate that normality assumption is violated. Panel (a) in Figure 2 is the normal probability plot of our model using its full sample $(n=67)$. Plots are remarkably coincident with the 45-degree line. RSTUDENT statistics, based on the studentized regression residuals, indicate that there is one observation that is above the threshold level of normality assumption. Panel $2 \mathrm{~b}$ is the normal probability plot after deleting this observation $(n=66)$. As expected, plots are closer to the 45 -degree line indicating an enhanced validity of normality assumption.

Now that we have identified the observation that is adversely influencing the normality assumption, the question is whether we should delete it from our regression sample. Deleting observations is certainly a drastic measure and potentially can cause different bias and other issues and therefore one would want to avoid that decision whenever possible. The key is whether the outcomes regarding the variables of our interest are sensible to this single observation. For example, if the signs of estimated coefficients alternate or the significance levels fluctuate then we would have a problem. It turns out, however, that such was not the case. Qualitative results from regressions with and without this observation were identical. We thus decided to retain this observation because i) the departure from normality assumption is not severe (Figure 2) and ii) adverse consequence of even smaller sample size could be more substantial than the benefit of deleting one observation.

In sum, we concluded that our empirical model with its full 67 observations can be used confidently in making inference on estimation results. 


\section{References}

Agrawal, A. 2001. Common property institutions and sustainable governance of resources. World Development 29(10), pp.1649-1672.

Baba, O. 1991. Fishery management under limited market: Case of pooling system in Suruga Bay sakuraebi fishery. In Studies on Fishery Management: Utilizing Limited Resources, Seizando Shoten, Tokyo. pp.176-186.

Baland, J.-M. and J.-P. Platteau. 1996. Halting Degradation of Natural Resources: Is there a Role for Rural Communities? New York: Oxford University Press.

Belsley, D. A., E. Kuh and R. E. Welsch. 1980. Regression Diagnostics. John Wiley \& Sons, New York.

Cancino, J. P., H. Uchida and J. E. Wilen. 2007. TURFs and ITQs: Collective vs. individual decision making. Marine Resource Economics 22, pp.391-406.

Cheung, S. N. S. 1970. The structure of a contract and the theory of a non-exclusive resource. Journal of Law and Economics 13(1), pp.49-70.

Christy, F. T. 1982. Territorial use rights in marine fisheries: Definitions and conditions. FAO Fisheries Technical Paper 227, p.10.

Cunningham, S. and T. Bostock. 2005. Successful Fisheries Management: Issues, Case Studies and Perspectives. Eburon Academic Publishers, Delft, The Netherlands.

Dillman, D. A. 1978. Mail and Telephone Surveys: The Total Design Method. John Willey\&Sons, New York.

Gaspart, F. and E. Seki. 2003. Cooperation, status seeking and competitive behaviour: theory and evidence. Journal of Economic Behavior \& Organization 51, pp.51-77.

Gordon, H. S. 1954. The Economic Theory of a Common-Property Resource: The Fishery. The Journal of Political Economy 62(2), pp.124-142.

Hasegawa, A. 1985. Pooling system in Suruga Bay sakuraebi fishery. In Restructuring Japanese fisheries: Part 2. Tokyo Fisheries Promotion Foundation (Tokyo Suisan Shinkokai), Tokyo. pp.59-88.

Herrmann, M. 1996. Estimating induced price increase for Canadian Pacific Halibut with the introduction of the individual vessel quota program. Canadian Journal of Agricultural Economics 44(2), pp.151-164.

Homans, F. R. and J. E. Wilen. 2005. Markets and rent dissipation in regulated open access. Journal of Environmental Economics and Management 49, pp.381-404.

Jentoft, S. 2003. Co-management-the way forward. In The fisheries co-management experience: Accomplishments, Challenges and Prospects, Fish and Fisheries Series. Kluwer Academic Publishers, Dordrecht, Netherlands, pp.1-14.

Johnston, R. J. and J. G. Sutinen. 2009. One Last Chance: The Economic Case for A New Approach to Fisheries Management in New England.

MAFF. 2006. The $11^{\text {th }}$ Fishery Census of Japan 2003. Ministry of Agriculture Forestry and Fisheries of Japan, Tokyo. (http://www.tdb.maff.go.jp/toukei/toukei). 
Makino, M. and H. Matsuda. 2005. Co-management in Japanese coastal fisheries: institutional features and transaction costs. Marine Policy 29(5), pp.441-450.

MOMAF. 2007. Fisher-Oriented Co-management Fisheries. October 14. (http://www.momaf/go.kr/english/fish/oriented/F_fishermen.asp).

Ostrom, E. 1990. Governing the commons: The evolution of institutions for collective action. The political economy of institutions and decisions. Cambridge University Press, Cambridge.

Ostrom, E., T. Dietz, N. Dol-ak, P. C. Stern, S. Stonich and E. U. Weber. 2002. The Drama of the Commons. National Academy Press, Washington, D.C.

Platteau, J.-P. and E. Seki. 2001. Community Arrangements to Overcome Market Failures: Pooling Groups in Japanese Fisheries. In Communities and Markets in Economic Development, Oxford University Press, New York, pp.344-402.

Sandler, T. 1992. Collective Action: Theory and Applications. University of Michigan Press, Ann Arbor.

Townsend, R. E., R. Shotton and H. Uchida. 2008. Case studies in fisheries self-governance. FAO Fisheries Technical Paper No. 504. FAO, Rome.

Uchida, H. 2004. Japanese coastal fisheries management and institutional designs: A descriptive analysis. In Twelfth Biennial Conference of International Institution of Fishery Economics and Trade. Tokyo. . 2009. Fishery comanagement for sustainable fishery: Lessons from Japan. In Economics of Rebuilding Fisheries, Organisation for Economic Co-operation and Development (OECD), Newport, RI, p.15

Uchida, H. and O. Baba. 2008. Fishery management and the pooling arrangement in the sakuraebi fishery in Japan. In Case studies in fisheries self-governance. FAO Fisheries Techinical Paper No. 504, FAO, Rome, pp.175-189.

Uchida, H. and M. Watanobe. 2008. Walleye pollack (suketoudara) fishery management in the Hiyama region of Hokkaido, Japan. In Case studies in fisheries self-governance, FAO Fisheries Techinical Paper No. 504. FAO, Rome, pp.163-173.

Wilson, D. C., J. R. Nielsen and P. Dengbol. 2003. The fisheries co-management experience: Accomplishments, challenges and prospects. Fish and Fisheries Series. Kluwer Academic Publishers, Dordrecht, Netherlands. 